\title{
Re: "Impact of direct-to-consumer advertising for hereditary breast cancer testing on genetic services at a managed care organization: A naturally occurring experiment"
}

\section{To the Editor:}

I read with interest in the article by Mouchawar et al. on the impact of direct-to-consumer advertising (DCA) for hereditary breast cancer testing. ${ }^{1}$ The authors are to be congratulated on an excellent study that will contribute to the understanding of the effect of DCA on the uptake of genetic counseling and testing.

I must take issue with the authors on one point. In the methods they state, "We acknowledge that the HFHS membership is ethnically different from KPCO. However, we expect any change in utilization of and access to cancer genetic services among insured women to be independent of race/ethnicity. .." There is evidence in the literature that indicates African American women are much less likely than Caucasian women to utilize genetic counseling/testing for Breast/Ovarian cancer. ${ }^{2-4}$ While I do not think this substantially affects the results of their study, reanalysis with exclusion of the African American women could confirm this.

Marc S. Williams MD, FAAP, FACMG Intermountain Healthcare Salt Lake City, Utah

\section{References}

1. Mouchawar J, Hensley-Alford S, Laurion S, Ellis J, Kulchak-Rahm A, Finucane ML et al. Impact of direct-to-consumer advertising for hereditary breast cancer testing on genetic services at a managed care organization: A naturally occurring experiment. Genet Med 2005;7:191-197.

2. Matthews AK, et al . Genetic testing of African Americans for susceptibility to inherited cancers: use of focus groups to determine factors contributing to participation. J Psychosoc Oncol 2000;18:1-19.

3. Lerman C, Hughes C, Benkendorf JL, Biesecker B, Kerner J, Willison J et al . Racial Differences in testing motivation and psychological distress following pretest education for BRCA1 gene testing. Cancer Epidemiol Biomarkers Prev 1999;8:361-367.

4. Hughes C, Gomez-Caminero A, Benkendorf J, Kerner J, Isaacs C, Barter J, et al. Ethnic differences in knowledge and attitudes about BRCA1 testing in women at increased risk. Patient Education and Counseling 1997;32:51-62. 